\title{
Board Games for Health: A Systematic Literature Review and Meta-Analysis
}

\author{
Andrea Gauthier, MScBMC, PhD Candidate, Pamela M. Kato, PhD, Kim C.M. Bul, PhD, \\ Ian Dunwell, $\mathrm{PhD}$, Aimee Walker-Clarke, MSc, PhD Candidate, and Petros Lameras, $\mathrm{PhD}^{2}$
}

\begin{abstract}
Nondigital board games are being used to engage players and impact outcomes in health and medicine across diverse populations and contexts. This systematic review and meta-analysis describes and summarizes their impact based on randomized and nonrandomized controlled trials. An electronic search resulted in a review of $n=21$ eligible studies. Sample sizes ranged from $n=17$ to $n=3110$ ( $n=6554$ total participants). A majority of the board game interventions focused on education to increase health-related knowledge and behaviors $(76 \%$, $n=16$ ). Outcomes evaluated included self-efficacy, attitudes/beliefs, biological health indicators, social functioning, anxiety, and executive functioning, in addition to knowledge and behaviors. Using the Cochrane Collaboration tool for assessing bias, most studies $(52 \%, n=11)$ had an unclear risk of bias $(33 \%$ [ $n=7]$ had a high risk and $14 \%[n=3]$ had a low risk). Statistical tests of publication bias were not significant. A randomeffects meta-analysis showed a large average effect of board games on health-related knowledge $\left(d^{*}=0.82\right.$, 95\% confidence interval; CI [0.15-1.48]), a small-to-moderate effect on behaviors $\left(d^{*}=0.33,95 \%\right.$ CI [0.16$0.51])$, and a small-to-moderate effect on biological health indicators $\left(d^{*}=0.37,95 \%\right.$ CI [0.21-0.52]). The findings contribute to the literature on games and gamified approaches in healthcare. Future research efforts should aim for more consistent high scientific standards in their evaluation protocols and reporting methodologies to provide a stronger evidence base.
\end{abstract}

Keywords: Board games, Serious games, Health education, Psychoeducation, Meta-analysis

\section{Introduction}

$\mathbf{T}$ HE APPLICATION OF game design approaches and technologies has gained popularity in healthcare as a means of creating more engaging interventions, which can improve knowledge, change real-world behaviors, and subsequently impact therapeutic outcomes. Successful examples exist in the areas of treatment adherence, pain management, physical rehabilitation, depression, schizophrenia, and phobias. ${ }^{1-6}$ Games can support engagement in play and fantasy, which are described as important mechanisms facilitating greater attentional control, enhanced learning and providing patient insight toward impacting long-term behaviors. ${ }^{7}$ From a theoretical perspective, it has been suggested that games stimulate or facilitate learning through immersion flow, and meeting individual's needs concerning mastery, fantasy, challenge, and connectedness. ${ }^{8-11}$
Although digital games are popular, nondigital formats have also been addressed in the research literature. ${ }^{12}$ Board games have a history of use in therapeutic contexts. ${ }^{13-15}$ Aside from its engaging and entertaining characteristics, one of the great advantages of using a board game is its ability to facilitate face-to-face interactions with peers, tutors, family members, or even a therapist. These social interactions are assumed to enhance learning opportunities. ${ }^{16}$ However, only a very small proportion of board games described in the literature have been evaluated to determine their impact. ${ }^{16}$ Reviews focusing on evaluating the use of board games in medical education, conclude that it would be premature to claim that board games have an impact on knowledge or other educational outcomes in medicine given the strength of the existing evidence reviewed. ${ }^{17,18}$ More recently, evaluations of board games for health with patients and community

\footnotetext{
${ }^{1}$ Faculty of Medicine, Institute of Medical Sciences, University of Toronto, Mississauga, Canada.

${ }^{2}$ Faculty of Engineering, Environment, and Computing, School of Computing, Electronics, and Mathematics, Coventry University, Coventry, United Kingdom.

${ }^{3}$ Faculty of Health and Life Sciences, Center for Innovative Research across the Life Course (CIRAL), Coventry University, Coventry, United Kingdom.

${ }^{4}$ Warwick Manufacturing Group, Department of Engineering Psychology, International Digital Laboratory, University of Warwick, Coventry, United Kingdom.
} 
members have demonstrated promising impacts on knowledge (e.g., knowledge of HIV and sexually transmitted diseases; STIs), ${ }^{19}$ health behaviors (e.g., improved food habits), ${ }^{20}$ and objective indicators of health (e.g., $\mathrm{HbA}_{1 \mathrm{c}}$ improvements among patients with Type II Diabetes). ${ }^{21}$ Results of these evaluations have not been synthesized or systematically assessed in the literature to date. Thus, there is a need to update previous reviews of board games in medical education and to expand the review, including evaluations of board games in other healthcare contexts.

The aim of this systematic review and meta-analysis is to answer the following two questions: (1) What kinds of board games targeting medical and health-related outcomes have been evaluated in the literature? and (2) What is the overall impact of these board games on health-related outcomes?

\section{Method}

This review follows the guidelines for the Preferred Reporting Items for Systematic Reviews and Meta-analyses (PRISMA). ${ }^{22,23}$ In conformity with these guidelines, the Supplementary Data (available online at https://www .liebertpub.com/suppl/doi/g4h.2018.0017) provide readers with additional detail regarding our method and results, while keeping the body of this article a manageable length. The Supplementary Data include detailed database search terms and strategies, elaborated descriptions of data collection and analysis methods, details of within-studies risk of bias (RoB) analyses (e.g., bias matrices and interrater reliability results), effect sizes (ES) for each outcome comparison included in this study, and expanded results of publication bias analyses.

\section{Inclusion and exclusion criteria}

In this article, board games are defined as "a game of strategy [...] played by moving pieces on a board," 24 which does not include games played exclusively with cards ("card games") or dice. Inclusion criteria were evaluations (1) of a health or medical-related nondigital board game intervention; (2) either as a standalone intervention or as part of a larger intervention program; (3) using random or other method of assignment to no treatment or active control group; (4) with participants from any sociodemographic background; (5) assessing medical and health-related outcomes; (6) of scholarly publications in a journal, thesis, research report, or conference proceeding; (7) published in English. Exclusion criteria were evaluations (1) of digital board games (i.e., played on computers or smart phones); (2) of board games not implemented as an intervention (e.g., used as an assessment tool); and (3) of a board game's impact on processes rather than outcomes (e.g., usability, acceptability, credibility). Notably, digital board games were not included because they breach into the category of digital game-based learning and often involve more complex gaming and learning mechanics, which would increase the heterogeneity of the included studies, rendering conclusions about overall efficacy more difficult to summarize. ${ }^{16}$

\section{Search method}

An electronic search was performed on five databases: ProQuest (encompassing ERIC, IBSS, PsycINFO), Scopus, PubMed, JSTOR, and OVID (encompassing Medline, Em- base). The search targeted board games specifically (term: "board game") in the area of health (terms: "health," "medical," "patient," "illness," “disease") (Supplementary Data for full search details). The searches were performed on February 8, 2017 and include studies available up until this date. Hand searching of the reference lists of articles that met final eligibility was also performed using the "snowball sampling" method. ${ }^{25}$

\section{Study selection}

Database search results were imported into RefWorks, where duplicates and non-scholarly publications were removed. The remaining abstracts were screened to exclude articles if a nondigital medical or health-related board game was not mentioned. The full texts of the remaining articles were reviewed in detail to see if they met the inclusion/exclusion criteria. Reasons for excluding articles were documented. Three researchers independently evaluated the articles for eligibility for inclusion. A fourth rater performed a reliability check of a random selection of 33\% of the articles for eligibility. Interrater reliability was calculated using Cohen's kappa $(\kappa)$ coefficient, where a value greater than 0.7 would be deemed acceptable. The raters met to discuss and resolve any discrepancies until $100 \%$ agreement was achieved.

\section{Data collection and data items}

For each included article, information such as the study design, participant characteristics, sample size, and means and standard deviations of measured outcomes at each recorded time point (preintervention, postintervention, delayed follow-up) were extracted (all data items are listed in the Supplementary Data).

To identify what aspects of health and medicine have been impacted by board games in the literature, we performed a preliminary inductive coding of the measures and outcomes in each article. Only outcomes that were measured for the board game group and one or more comparison groups were coded. Following the preliminary coding, the primary coder and another investigator held a meeting to refine the coding scheme until $100 \%$ agreement on codes was reached.

\section{Data analyses}

Summary measures. Based on the extracted detailed data, the ES and $95 \%$ confidence intervals (CIs) were calculated using Cohen's $d$, based on a between-group mean difference for each continuous data outcome at each time point (preintervention, postintervention, delayed follow-up). ${ }^{26}$ For dichotomous data, ES and standard errors were first calculated with a log odds ratio (using natural logarithm) then converted to Cohen's $d$ by the method described in Borenstein et al. (p. 47), ${ }^{27}$ to establish comparability. Special considerations in the ES calculation were made for studies with a cluster randomized design, for studies with multiple comparison groups, and for studies with multiple outcome measures within the same outcome category (Supplementary Data). ${ }^{28}$

Since most outcome measurements extracted from the included studies did not report variance metrics for pre-topostintervention change/improvement (only $7.4 \%$ of outcomes included these data), our analysis focused on ES comparing postintervention scores between experimental groups and, when 
reported, delayed follow-up scores. The ES of preintervention scores were taken into account when evaluating the RoB for each comparison. Where negative ES represented a preferred outcome (e.g., age- and sex-adjusted body mass index (zBMI) as related to obesity, or reduction in positive attitudes toward cigarette smoking), these results were multiplied by -1 to reflect a positive result in the meta-analysis.

Synthesis of data. It has been argued that combining heterogeneous studies may be appropriate if the purpose of the analysis is to come to higher-order generalizations about the topic in question. ${ }^{29,30}$ As such, this review combines heterogeneous studies investigating an array of board games and populations to answer our research questions. A summary of inconsistency across studies for each outcome is given by the value $I^{2}$ under each table summarizing the metaanalysis. $^{28}$ For each outcome measure category (e.g., knowledge, behavior, self-efficacy, etc.)—and separately for both postintervention and delayed follow-up time pointsthe following random-effects meta-analyses are produced when two or more data points were available:

1. An overall analysis that synthesizes all comparisons, where an ES could be calculated (Summary Measures section).

2. A sensitivity analysis using only outcome comparisons at a low RoB.

\section{Risk of bias}

RoB in individual studies. For each extracted outcome measure, its RoB was assessed using the Cochrane Collaboration tool for assessing $\mathrm{RoB},{ }^{28}$ where six categories of bias (selection bias, performance bias, detection bias, attrition bias, reporting bias, and other bias) were evaluated. These categories were judged as either "low risk," if the bias was unlikely to affect the study's results; "unclear risk," if the information was not included or was insufficient; or "high risk," if the bias would seriously affect confidence in the results. Two raters assessed risk in each study and interrater reliability for each category of bias was calculated using Cohen's kappa coefficient, where a value greater than 0.7 was deemed acceptable. Discrepancies between the two assessors were identified, discussed, and resolved with $100 \%$ agreement.

RoB across studies. The inverse standard error and the weighted variance for each study's combined $d$ statistic were calculated to investigate the risk of publication bias across studies visually with a funnel plot. Egger's regression test was used to assess the (1) overall publication bias in the literature (i.e., across outcomes) at postintervention and delayed follow-up separately, and (2) for each outcome category individually, at the postintervention time point. For the analysis across all outcomes, to avoid a unit-of-analysis error, all results from each study were combined into a single ES (Supplementary Data: Summary Measures section).

\section{Results}

\section{Study selection}

Our electronic database search resulted in a total of $n=1043$ articles from ProQuest $(n=578)$, Scopus $(n=185)$,
PubMed $(n=55)$, JSTOR $(n=18)$, and OVID $(n=207)$, whereas another three $(n=3)$ other references were identified as potential candidates based on a "snowball" search of the reference lists of eligible articles. Figure 1 documents the study selection process. A total of 22 articles met our inclusion/exclusion criteria; however, $n=2$ articles reported the same outcomes and intervention. ${ }^{31,32}$ Data from these two articles were extracted, summarized, and considered as one article, resulting in 21 total selected studies. Additionally, two of the articles evaluated the same board game reported on different outcomes in two distinctly different studies. ${ }^{20,33}$ They are thus considered separate studies of one board game in this report. Interrater reliability on the study selection process was high, with $\kappa=0.86$ and a $97.92 \%$ agreement rate.

\section{Study characteristics}

Table 1 summarizes study characteristics across the 21 research studies, including study designs, sample/cluster sizes, populations/locations, and play duration, whereas the details of each board game intervention (i.e., purpose, general intervention structure, and mechanics employed) are presented in Table 2 .

Study design. Studies consisted of $n=11$ randomized controlled trials; $n=4$ cluster randomized controlled trials; and $n=6$ quasi-experimental or nonrandomized trials, one of which was a case-control trial. Most of the studies $(n=16)$ included a "no intervention" or a standard of care/learning comparison group. Two studies compared the board game with other educational media, ${ }^{34,35}$ and four compared the board game with an educational lecture. ${ }^{19,31,32,36,37}$ Finally, two studies included a specialized training intervention as control that mirrored the content/experiences targeted in the board game. $^{38,39}$

Sample sizes. Studies varied in sample size, from small $(n=17)^{40}$ to large $(n=3110$ across 20 clusters $){ }^{20}$ with $n=6554$ total participants across all 21 studies. Of these, $n=3055$ received a board game-based intervention and $n=3499$ were in a comparison/control group.

Populations. The samples used to evaluate the board games included a wide range of age groups, from children as young as 8 years old ${ }^{35}$ to older adults. ${ }^{40}$ Most $(57 \%, n=12)$ of the studies' participants were students enrolled in school. Participants in the remaining $n=9 / 21$ studies (who were not students enrolled in schools) were patients in $n=6$ studies and people recruited from specific communities in the remaining $n=3$ studies.

Duration of play. Interventions varied in total play-time reported ranging from 5 minutes ${ }^{38}$ to 30 hours, ${ }^{40}$ and in overall duration of intervention, from a single session to 24 weeks. ${ }^{33}$

\section{Description of the board game interventions}

Purposelaims of the board game interventions. Most of the board game interventions focused on education to increase knowledge and/or skills ( $n=17 / 21$ studies representing 16 board games). The remaining board games evaluated 


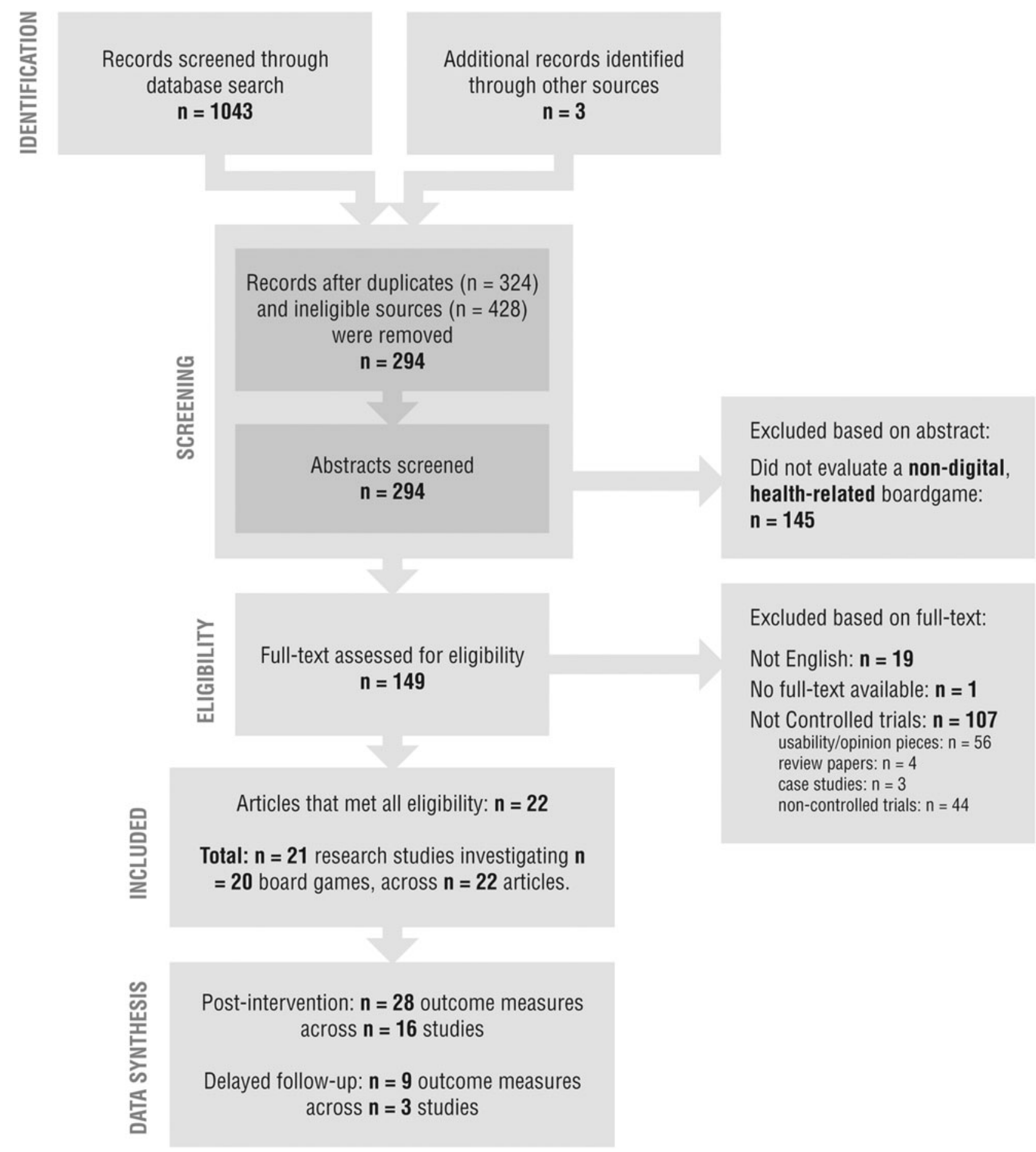

FIG. 1. Flow diagram of study selection process.

in $n=4 / 21$ studies aimed to directly impact a neurological skill (i.e., cognitive functioning for community seniors), ${ }^{40}$ physical rehabilitation skills (i.e., hand pinch strength), ${ }^{38}$ increase interest in Global Health issues, ${ }^{41}$ or change in motivations among community members to increase their intentions to seek local pharmacy advice. ${ }^{42}$

General intervention structure. Most of the included studies ( $n=15$ studies, representing $n=14$ board games) evaluated a board game in itself as an intervention, whereas $n=6$ studies investigated the effect of a board game as part of a multicomponent intervention program.

Game design and mechanics. The mechanics for only $n=15 / 20$ board games could be interpreted (Table 2 ). Notably, most games $(n=12)$ were competitive in nature. The most popular learning mechanic implemented in the board game was a question-and-answer (self-testing) strategy, with 


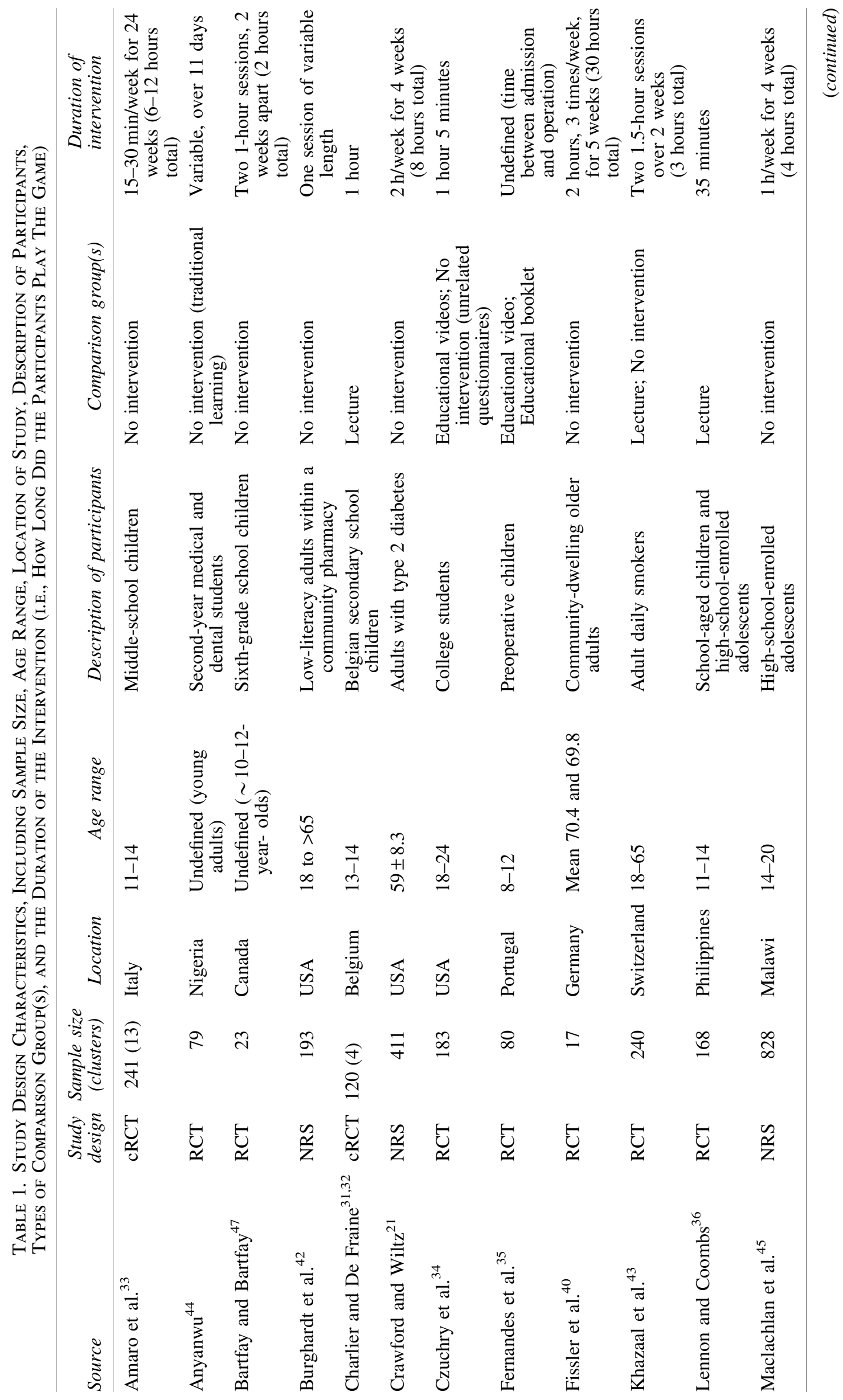




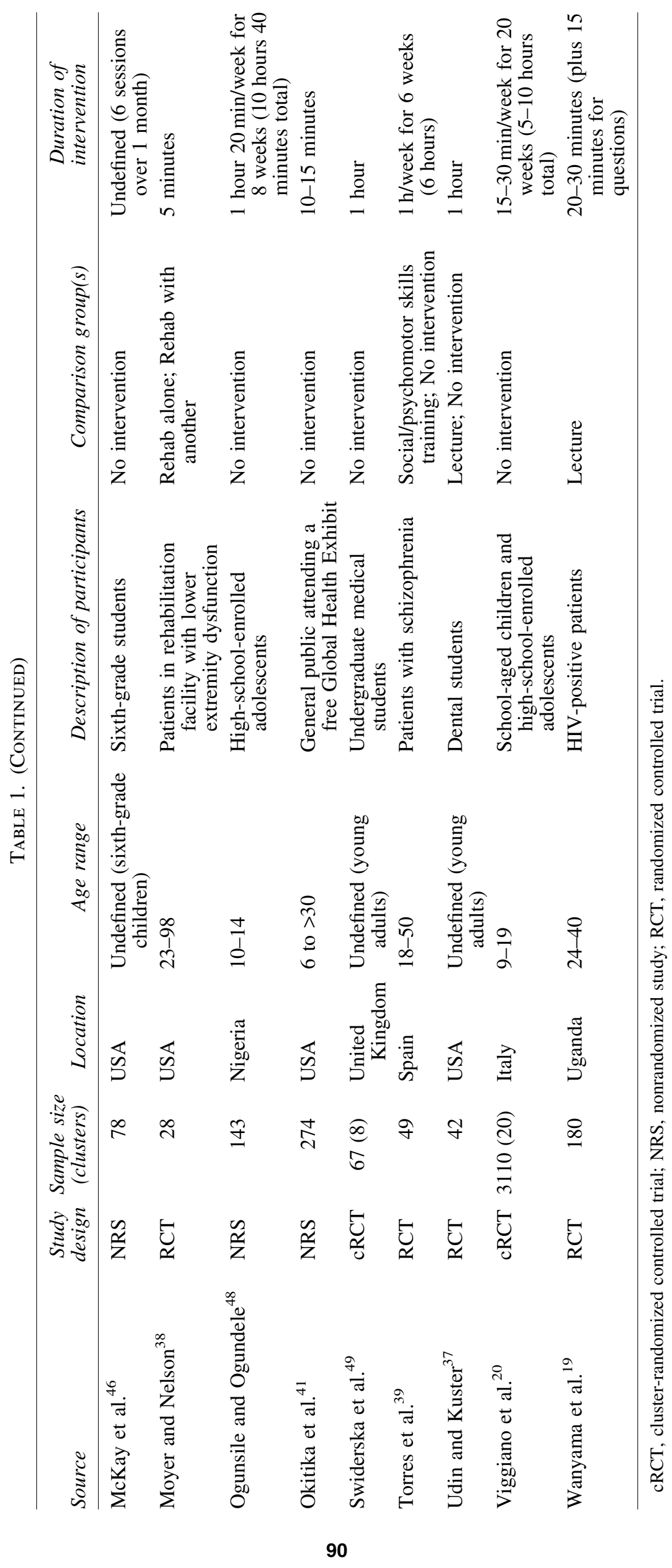




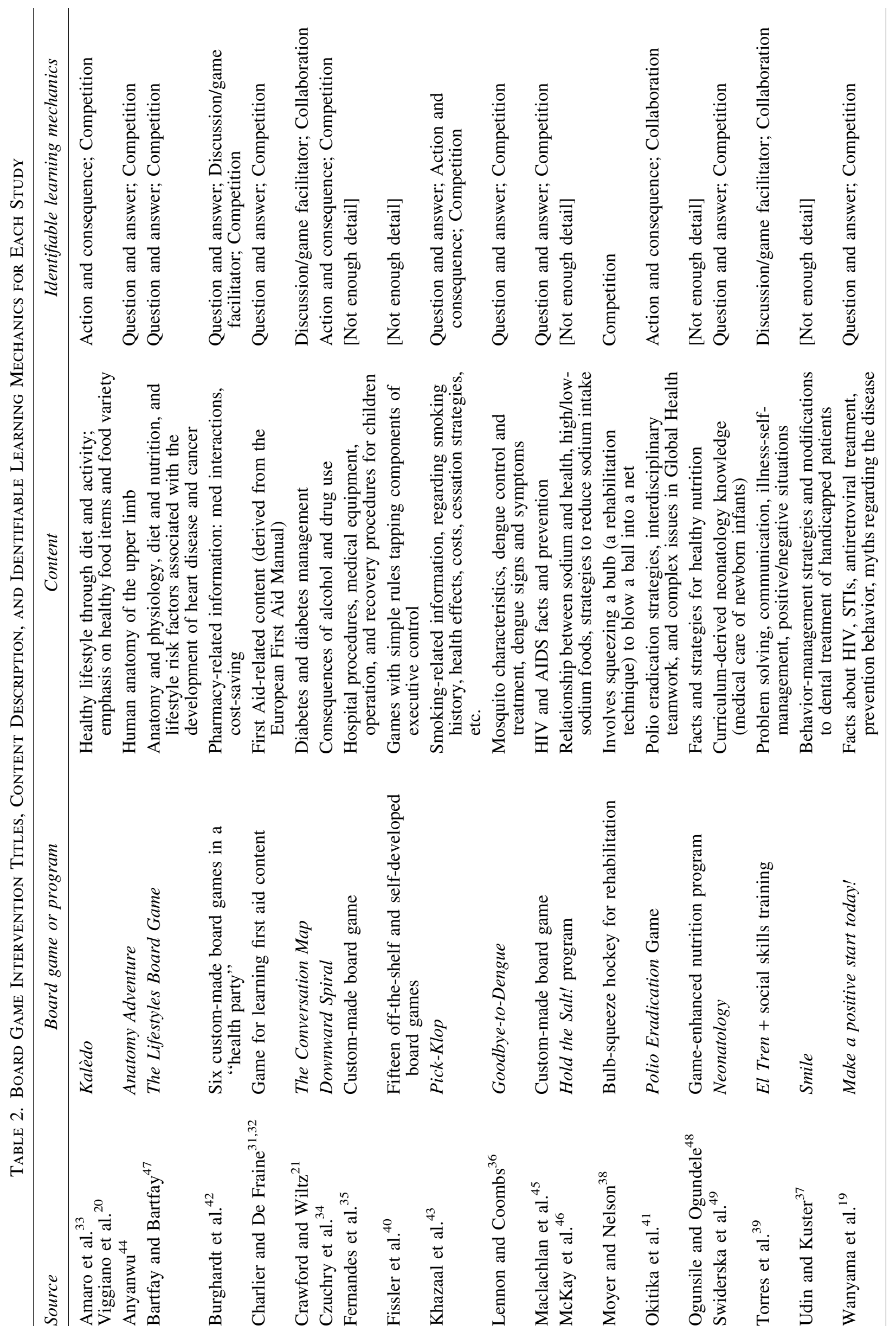


Table 3. The Number of Studies, Measures, and Game-Control Comparisons Extracted FROM the Literature in EACH Outcome CATEgory

\begin{tabular}{|c|c|c|c|c|c|c|c|c|}
\hline \multirow[b]{2}{*}{ Outcome } & \multirow[b]{2}{*}{ Studies } & \multirow[b]{2}{*}{ Measures } & \multicolumn{3}{|c|}{ Postintervention comparisons ${ }^{\mathrm{a}}$} & \multicolumn{3}{|c|}{ Delayed follow-up comparisons $\mathrm{s}^{\mathrm{a}}$} \\
\hline & & & Overall & $\begin{array}{c}M A-\text { all } \\
R o B\end{array}$ & $\begin{array}{c}M A-l o w \\
R o B\end{array}$ & Overall & $\begin{array}{c}M A-\text { all } \\
R o B\end{array}$ & $\begin{array}{c}M A-\text { low } \\
\text { RoB }\end{array}$ \\
\hline Behavior $b$ & 10 & 19 & 28 & 8 & 2 & 7 & 2 & 2 \\
\hline Self-reported behavior & 5 & 10 & 12 & 4 & 2 & 7 & 2 & 2 \\
\hline Behavioral intentions & 4 & 7 & 12 & 3 & 0 & 0 & 0 & 0 \\
\hline Measured behavior & 1 & 2 & 4 & 1 & 0 & 0 & 0 & 0 \\
\hline Knowledge & 11 & 13 & 13 & 8 & 2 & 2 & 2 & 1 \\
\hline Self-efficacy & 4 & 5 & 7 & 3 & 2 & 4 & 2 & 2 \\
\hline Attitudes and beliefs & 6 & 10 & 15 & 4 & 2 & 11 & 2 & 2 \\
\hline Biological health indicators & 3 & 5 & 6 & 3 & 1 & 1 & 1 & 1 \\
\hline Social functioning & 1 & 7 & 14 & 1 & 0 & 0 & 0 & 0 \\
\hline Anxiety & 1 & 2 & 4 & 0 & 0 & 0 & 0 & 0 \\
\hline Executive functioning & 1 & 1 & 1 & 1 & 0 & 0 & 0 & 0 \\
\hline Total & $(21)$ & 62 & 88 & 28 & 9 & 25 & 9 & 8 \\
\hline
\end{tabular}

"The number of comparisons in the "Overall" column indicates the raw number of game-control comparisons reported in the studies. The "MA-all RoB" reports the total number of comparisons included in the data synthesis for each category after combining for multiple control groups or multiple measures from the same study. The "MA-low RoB" reports the total number of comparisons at a low RoB included in the sensitivity analyses.

b" Behavior" category includes the three subcategories of "self-reported behavior," "behavioral intentions," and "measured behavior." MA, meta-analysis; RoB, risk of bias.

$n=9$ interventions employing this mechanic as their primary method of learning. In all cases, progressing in the game required questions to be answered correctly. In contrast, $n=4$ board games implemented an action-and-consequence style of learning mechanic that involved a more reflective learning. For example, to affect diet and lifestyle behavior in children, Kalèdo employs nutrition and activity cards that the children must balance to optimize calorie-intake and energy expenditure; furthermore, the player faces consequences (e.g., loss or gain of points) throughout the game for real-life dietary/exercise decisions made during the day, thereby enhancing their understanding of healthy and unhealthy behavior and encouraging real-world transfer. ${ }^{20,33}$

Outcomes assessed. Coding of the outcome measures resulted in eight categories of health-related outcomes across the studies: (1) health-related behavior (including selfreported behavior, self-reported behavioral intentions, and measured behaviors), (2) knowledge (of a health concept or skill), (3) self-efficacy (perceived confidence in one's abilities to carry out a health-related behavior), (4) attitudes and beliefs about a health concept, (5) biological health indicators, (6) social functioning, (7) anxiety, and (8) executive functioning. The distribution of studies, measures, and between-group comparisons across outcome categories are presented in $\mathrm{Ta}-$ ble 3. Hereafter, we use the term "outcome" to refer to the construct that was measured; the "measure" to refer to the method or means used to quantify the outcome; and "comparison" to refer to a between-group analysis of two or more comparisons between groups for a single measure (e.g., game vs. no intervention, game vs. lecture).

\section{RoB within studies}

Overall, $n=3$ studies were considered to have an overall low $\operatorname{RoB}^{19,20,43} ; n=7$ were considered to have an overall high $\operatorname{RoB}^{31,32,35,41,42,44-46}$; and $n=11$ were considered to have an unclear RoB. ${ }^{21,33,34,36-40,47-49}$ RoB matrices for each outcome category and interrater reliability statistics are reported in the Supplementary Data. Table 3 also presents the number of low RoB and other comparisons suitable for inclusion in the data synthesis.

\section{Results by type of outcome}

Below, we present the syntheses of between-group mean difference ES (Cohen's $d$ ) for each study categorized by the type of outcome measurement at both the postintervention and delayed follow-up (if applicable) time points (visualized in Fig. 2). Overall synthetic analyses (using comparisons at all levels of RoB) and sensitivity analyses (using only comparisons at a low RoB) are presented. An ES given as " $d^{*}$ " denotes a synthesized effect across two or more studies, whereas " $d$ " denotes an effect within a single study. A summary of the RoB across studies in each category is included in each subsection.

Health-related behavior. Health-related behaviors are made up of the subcategories of self-reported behavior, behavioral intentions, and measured behaviors. Taken together, health behaviors showed a small-to-moderate effect in favor of board games compared with control group(s) at immediate postintervention assessment $\left(d^{*}=0.33,95 \%\right.$ CI [0.16-0.51], $\mathrm{Q}=18.90, d f=7, \mathrm{C}=373.59, \mathrm{Tau}=0.03, I^{2}=62.97 \%, \mathrm{Z}=3.83$, $P<0.001)$ and a small effect in favor of board games at delayed follow-up $\left(d^{*}=0.24,95 \%\right.$ CI [0.02-0.45], Q=1.86, $d f=1$, $\mathrm{C}=70.45$, Tau $\left.=0.01, I^{2}=46.24 \%, \mathrm{Z}=2.18, P=0.029\right)$. Each subcategory of health-related behavior is discussed individually in more detail below.

Self-reported behavior. In the subcategory of self-reported health behaviors (Table 4), we observe a significant small-tomoderate effect in favor of board games $\left(d^{*}=0.38,95 \% \mathrm{CI}\right.$ [0.07-0.69]) over other control conditions immediately after 

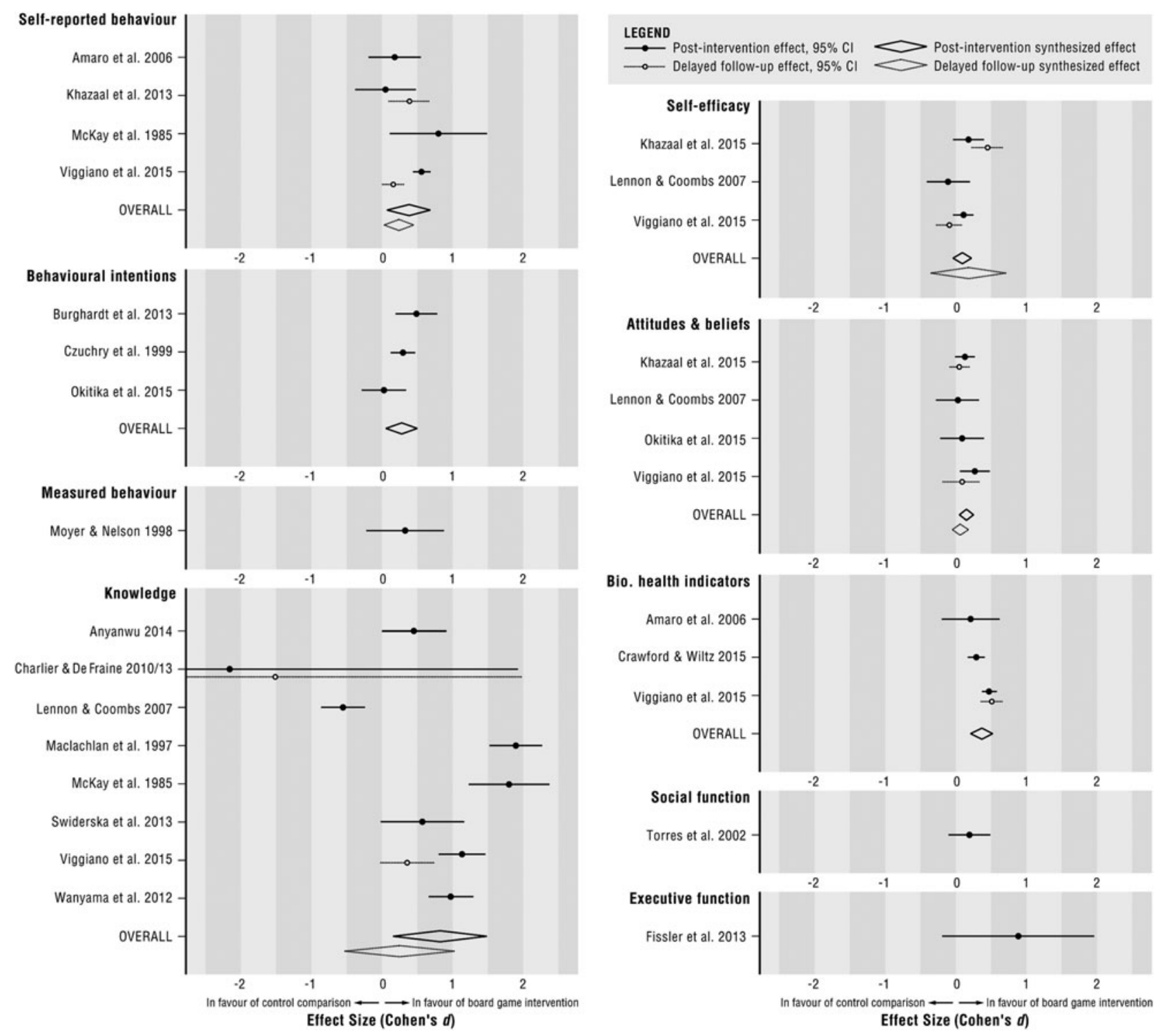

FIG. 2. Forest plots of effect sizes at the postintervention and delayed postintervention time points, displaying results at all levels of risk of bias (diamonds). Refer to Table 4 through Table 9 for details.

Table 4. Effect Size Details for Studies Measuring Self-Reported Health-Related Behavior

\begin{tabular}{|c|c|c|c|c|c|c|}
\hline \multirow[b]{2}{*}{ Source } & \multirow[b]{2}{*}{ Comps } & \multirow[b]{2}{*}{$\operatorname{RoB}$} & \multicolumn{2}{|l|}{ Postintervention } & \multicolumn{2}{|c|}{ Delayed follow-up } \\
\hline & & & ES (95\% CI low to high) & Weight (\%) & ES (95\% CI low to high) & Weight (\% \\
\hline \multicolumn{7}{|c|}{ A. Synthesis of data at all RoB } \\
\hline Amaro et al. ${ }^{33}$ & 2 & Unclear & $0.18(-0.19$ to 0.55$)$ & 25.5 & - & - \\
\hline Khazaal et al. ${ }^{43}$ & 4 & Low/unclear & $0.05(-0.38$ to 0.48$)$ & 22.8 & $0.39(0.10-0.68)$ & 34.7 \\
\hline McKay et al. ${ }^{46}$ & 2 & High & $0.80(0.11-1.49)$ & 13.3 & - & - \\
\hline Viggiano et al. ${ }^{20}$ & 3 & Low & $0.56(0.44-0.69)$ & 38.5 & $0.16(0.01-0.31)$ & 65.3 \\
\hline Synthesized effect & & & $0.38(0.07-0.69)^{\mathrm{a}}$ & & $0.24(0.02-0.45)^{\mathrm{b}}$ & \\
\hline \multicolumn{7}{|c|}{ B. Synthesis of data at low RoB } \\
\hline Khazaal et al. ${ }^{43}$ & 3 & Low & $0.09(-0.36$ to 0.54$)$ & 39.2 & $0.40(0.08-0.73)$ & 32.7 \\
\hline Viggiano et al. ${ }^{20}$ & 3 & Low & $0.56(0.44-0.69)$ & 60.8 & $0.16(0.01-0.31)$ & 67.3 \\
\hline Synthesized effect & & & $0.38(0.08-0.83)^{\mathrm{c}}$ & & $0.24(0.01-0.46)^{\mathrm{d}}$ & \\
\hline
\end{tabular}

ES, (Cohen's $d$ ); "Comps" refers to the number of game-control comparisons that were combined (due to multiple outcome measures or multiple control groups) to form the ES used. "Weight (\%)" refers to the total weight or contribution each study makes to the synthesized effect.

${ }^{\mathrm{a}} \mathrm{Q}=8.84, d f=3, \mathrm{C}=99.06$, $\mathrm{Tau}=0.06, I^{2}=66.07, \mathrm{Z}=2.44, P=0.015$.

${ }^{\mathrm{b}} \mathrm{Q}=1.86, d f=1, \mathrm{C}=70.45$, Tau $=0.01, I^{2}=46.24, \mathrm{Z}=2.18, P=0.029$.

${ }^{\mathrm{c}} \mathrm{Q}=3.96, d f=1, \mathrm{C}=35.11$, Tau $=0.08, I^{2}=74.76, \mathrm{Z}=1.62, P=0.104$.

${ }^{\mathrm{d}} \mathrm{Q}=1.82, d f=1, \mathrm{C}=60.55$, Tau $=0.01, I^{2}=44.98, \mathrm{Z}=2.08, P=0.038$.

ES, effect size. 
Table 5. Effect Sizes for Studies Measuring Health-Related Behavioral Intentions

\begin{tabular}{|c|c|c|c|c|c|c|}
\hline \multirow[b]{2}{*}{ Source } & \multirow[b]{2}{*}{ Comps } & \multirow[b]{2}{*}{$R o B$} & \multicolumn{2}{|c|}{ Postintervention } & \multicolumn{2}{|c|}{ Delayed follow-up } \\
\hline & & & ES (95\% CI low to high) & Weight (\%) & ES (95\% CI low to high) & Weight (\%) \\
\hline $\begin{array}{l}\text { Burghardt et al. }{ }^{42} \\
\text { Czuchry et al. }{ }^{34} \\
\text { Okitika et al. }{ }^{4} \\
\text { Synthesized effect }\end{array}$ & $\begin{array}{l}1 \\
8 \\
1\end{array}$ & $\begin{array}{l}\text { Unclear } \\
\text { Unclear } \\
\text { Unclear }\end{array}$ & $\begin{array}{l}0.48(0.19-0.78) \\
0.30(0.12-0.47) \\
0.03(-0.29 \text { to } 0.34) \\
0.28(0.06-0.50)^{\mathrm{a}}\end{array}$ & $\begin{array}{l}29.1 \\
44.3 \\
26.5\end{array}$ & $\begin{array}{l}- \\
-\end{array}$ & - \\
\hline
\end{tabular}

ES (Cohen's $d$ ); "Comps" refers to the number of game-control comparisons that were combined (due to multiple outcome measures or multiple control groups) to form the ES used. "Weight (\%)" refers to the total weight or contribution each study makes to the synthesized effect.

${ }^{\mathrm{a}} \mathrm{Q}=4.36, d f=2, \mathrm{C}=116.94, \mathrm{Tau}=0.02, I^{2}=54.13, \mathrm{Z}=2.51, P=0.012$.

the intervention takes place. Additionally, we see a small effect at delayed follow-up $\left(d^{*}=0.24,95 \%\right.$ CI [0.02-0.45]). Overall, the RoB associated with self-reported behavior outcomes was deemed to be "unclear," with $\sim 56 \%$ of the weight at a low RoB, $\sim 31 \%$ at an unclear RoB, and $13.3 \%$ at a high RoB. However, sensitivity analyses - that include only comparisons at a low RoB-show similar effects at both the postintervention $\left(d^{*}=0.38,95 \%\right.$ CI [0.08-0.83]) and delayed follow-up $\left(d^{*}=0.24,95 \%\right.$ CI $\left.[0.01-0.46]\right)$.

Behavioral intentions. Behavioral intentions as a subcategory are considered distinct from self-reported behaviors because they measure intent to engage in behaviors in the future, as opposed to self-reported behaviors that occurred in the past. A small effect of board games over control groups is observed for behavioral intentions postintervention $\left(d^{*}=0.28,95 \% \mathrm{CI}[0.06\right.$ 0.50]; Table 5). No study measured behavioral intentions at delayed follow-up. The RoB associated with comparisons measuring behavioral intentions is high overall, with $44.3 \%$ weighted as "unclear" RoB, and 55.6\% as high RoB. No study provided low RoB comparisons, so sensitivity analyses were not performed.
Measured behavior. Finally, Moyer and Nelson assessed the subcategory of health-related behavior directly, with hand pinch strength (pressure) and pinch repetitions in individuals attending rehabilitation sessions. ${ }^{38}$ Combining multiple comparisons in this study, no effect of board game over the control group was observed $(d=0.33,95 \% \mathrm{CI}$ [ -0.22 to 0.88$], \mathrm{Z}=1.18, P=0.239)$. This comparison has an overall unclear RoB.

Knowledge. A large and significant postintervention effect of health/disease-related knowledge in favor of board games was observed at immediate follow-up $\left(d^{*}=0.82,95 \%\right.$ CI [0.15-1.48]). The effect was small and not significant at the delayed follow-up $\left(d^{*}=0.25,95 \%\right.$ CI [ -0.53 to 1.03$\left.]\right)$. Heterogeneity of the postintervention ES was very high $\left(I^{2}=94.50 \%\right)$ and included studies measuring very different types of knowledge. The synthesis of ES for health-related knowledge outcomes have only $28.7 \%$ of the weight associated with low RoB, $27.6 \%$ with high RoB, and $43.8 \%$ with an unclear RoB. Using only low RoB ES, the large postintervention ES remains $\left(d^{*}=1.05,95 \%\right.$ CI [0.82-1.28]), and the one study ${ }^{20}$ that did a delayed follow-up assessment

Table 6. Effect Sizes for Studies Measuring Health-Related Knowledge

\begin{tabular}{|c|c|c|c|c|c|c|}
\hline \multirow[b]{2}{*}{ Source } & \multirow[b]{2}{*}{ Comps } & \multirow[b]{2}{*}{$\operatorname{RoB}$} & \multicolumn{2}{|l|}{ Postintervention } & \multicolumn{2}{|l|}{ Delayed follow-up } \\
\hline & & & ES (95\% CI low to high) & $\begin{array}{c}\text { Weight } \\
(\%)\end{array}$ & ES (95\% CI low to high) & $\begin{array}{c}\text { Weight } \\
(\%)\end{array}$ \\
\hline \multicolumn{7}{|l|}{ A. Synthesis of data at all RoB } \\
\hline Anyanwu 44 & 1 & Unclear & $0.45(0.00-0.91)$ & 13.9 & - & - \\
\hline Charlier and De Fraine ${ }^{31,32}$ & 1 & Unclear & $-2.15(-6.22$ to 1.92$)$ & 2.3 & $-1.51(-4.99$ to 1.96$)$ & 4.9 \\
\hline Lennon and Coombs ${ }^{36}$ & 1 & Unclear & $-0.55(-0.86$ to 0.24$)$ & 14.4 & - & - \\
\hline Maclachlan et al. ${ }^{45}$ & 1 & High & $1.89(1.52-2.26)$ & 14.2 & - & - \\
\hline McKay et al. ${ }^{46}$ & 1 & High & $1.76(1.19-2.32)$ & 13.4 & - & - \\
\hline Swiderska et al. ${ }^{49}$ & 1 & Unclear & $0.57(-0.02$ to 1.16$)$ & 13.3 & - & - \\
\hline Viggiano et al. $^{20}$ & 1 & Low & $1.13(0.80-1.46)$ & 14.3 & $0.34(-0.03$ to 0.72$)$ & 95.1 \\
\hline Wanyama et al. ${ }^{19}$ & 1 & Low & $0.97(0.66-1.29)$ & 14.4 & - & - \\
\hline Synthesized effect & & & $0.82(0.15-1.48)^{\mathrm{a}}$ & & $0.25(-0.53 \text { to } 1.03)^{\mathrm{b}}$ & \\
\hline \multicolumn{7}{|l|}{ B. Synthesis of data at low RoB } \\
\hline Viggiano et al. ${ }^{20}$ & 1 & Low & $1.13(0.80-1.46)$ & 46.9 & $0.34(-0.03$ to 0.72$)$ & 100 \\
\hline Wanyama et al. ${ }^{19}$ & 1 & Low & $0.97(0.66-1.29)$ & 53.1 & - & - \\
\hline Synthesized effect & & & $1.05(0.82-1.28)^{\mathrm{c}}$ & & & \\
\hline
\end{tabular}

ES (Cohen's $d$ ); "Comps" refers to the number of game-control comparisons that were combined (due to multiple outcome measures or multiple control groups) to form the ES used. "Weight (\%)" refers to the total weight or contribution each study makes to the synthesized effect.

${ }^{\mathrm{a}} \mathrm{Q}=127.18, d f=7, \mathrm{C}=153.19, \mathrm{Tau}=0.78, I^{2}=94.50, \mathrm{Z}=2.39, P=0.017$.

${ }^{\mathrm{b}} \mathrm{Q}=1.08, d f=1, \mathrm{C}=0.63$, Tau $=0.13, I^{2}=7.58, \mathrm{Z}=0.64, P=0.525$.

${ }^{\mathrm{c}} \mathrm{Q}=0.48, d f=1, \mathrm{C}=37.29$, Tau $=0.00, I^{2}=0.00, \mathrm{Z}=9.08, P=0.001$. 
Table 7. Effect Sizes for Studies Measuring Health-Related Self-Efficacy

\begin{tabular}{|c|c|c|c|c|c|c|}
\hline \multirow[b]{2}{*}{ Source } & \multirow[b]{2}{*}{ Comps } & \multirow[b]{2}{*}{$\operatorname{RoB}$} & \multicolumn{2}{|l|}{ Postintervention } & \multicolumn{2}{|l|}{ Delayed follow-up } \\
\hline & & & ES (95\% CI low to high) & $\begin{array}{c}\text { Weight } \\
(\%)\end{array}$ & ES (95\% CI low to high) & $\begin{array}{c}\text { Weight } \\
(\%)\end{array}$ \\
\hline \multicolumn{7}{|c|}{ A. Synthesis of data at all RoB } \\
\hline Khazaal et al. ${ }^{43}$ & 2 & Low/unclear & $0.18(-0.04$ to 0.40$)$ & 28.7 & $0.45(0.23-0.68)$ & 49.2 \\
\hline Lennon and Coombs ${ }^{36}$ & 1 & Unclear & $-0.11(-0.41$ to 0.20$)$ & 16.2 & - & - \\
\hline $\begin{array}{l}\text { Viggiano et al. } \\
\text { Synthesized effect }\end{array}$ & 2 & Low & $\begin{array}{l}0.11(0.04 \text { to } 0.25) \\
0.09(-0.03 \text { to } 0.22)^{\mathrm{a}}\end{array}$ & 55.1 & $\begin{array}{r}-0.09(-0.27 \text { to } 0.08) \\
0.18(-0.36 \text { to } 0.71)^{b}\end{array}$ & 50.8 \\
\hline \multicolumn{7}{|c|}{ B. Synthesis of data at low RoB } \\
\hline Khazaal et al. ${ }^{43}$ & 1 & Low & $0.16(-0.16$ to 0.47$)$ & 18.2 & $0.5(0.17-0.80)$ & 47.3 \\
\hline $\begin{array}{l}\text { Viggiano et al. } \\
\text { Synthesized effect }\end{array}$ & 2 & Low & $\begin{array}{l}0.11(-0.04 \text { to } 0.25) \\
0.12(-0.02 \text { to } 0.25)^{\mathrm{c}}\end{array}$ & 81.8 & $\begin{array}{l}-0.1(-0.27 \text { to } 0.08) \\
0.18(-0.39 \text { to } 0.75)^{\mathrm{d}}\end{array}$ & 52.7 \\
\hline
\end{tabular}

ES (Cohen's $d$ ); "Comps" refers to the number of game-control comparisons that were combined (due to multiple outcome measures or multiple control groups) to form the ES used. "Weight (\%)" refers to the total weight or contribution each study makes to the synthesized effect.

${ }^{\mathrm{a}} \mathrm{Q}=2.35, d f=2, \mathrm{C}=165.16$, Tau $=0.00, I^{2}=14.76, \mathrm{Z}=1.43, P=0.151$.

${ }^{\mathrm{b}} \mathrm{Q}=14.30, d f=1, \mathrm{C}=95.18$, Tau $=0.14, I^{2}=93.01, \mathrm{Z}=0.64, P=0.523$.

${ }^{\mathrm{c}} \mathrm{Q}=0.08, d f=1, \mathrm{C}=64.57$, Tau $=0.00, I^{2}=0.00, \mathrm{Z}=1.70, P=0.089$.

${ }^{\mathrm{d}} \mathrm{Q}=9.88, d f=1, \mathrm{C}=58.97$, Tau $=0.15, I^{2}=89.88, \mathrm{Z}=0.62, P=0.534$.

of knowledge shows a marginally significant small-tomoderate effect $(d=0.34,95 \%$ CI [ -0.03 to 0.72$], p=.063)$. Refer to Table 6 for details.

Self-efficacy. Self-efficacy refers to an individual's self-perceived abilities to engage in behaviors despite challenges. ${ }^{50}$ The mean ES for self-efficacy showed no evidence of an effect at immediate $\left(d^{*}=0.09,95 \% \mathrm{CI}\right.$ $[-0.03$ to 0.22$])$ or at delayed follow-up $\left(d^{*}=0.18,95 \% \mathrm{CI}\right.$ [-0.36 to 0.71$]$ ), Table 7 . The comparisons for self-efficacy are at an overall low RoB, with $\sim 69 \%$ of weighted data at low risk and $\sim 31 \%$ at an unclear risk. Results are consistent with the overall synthesis (above) when analyzing only comparisons with a low RoB at the posttest $\left(d^{*}=0.12,95 \%\right.$ CI $[-0.02$ to 0.25$])$ and delayed follow-up $\left(d^{*}=0.18,95 \%\right.$ CI $[-0.39$ to 0.75$])$.
Attitudes and beliefs. Participants' attitudes and beliefs about a health topic showed a small but significant effect in favor of board games postintervention $\left(d^{*}=0.15,95 \% \mathrm{CI}\right.$ [0.05-0.25]), but not at delayed follow-up $\left(d^{*}=0.06,95 \% \mathrm{CI}\right.$ [ -0.05 to 0.18$])$, Table 8 . The comparisons associated with health-related attitudes and beliefs are largely at a low RoB, with $\sim 72 \%$ weighted at low RoB, $\sim 17 \%$ at an unclear RoB, and $\sim 11 \%$ at a high RoB. Sensitivity analyses using only low-RoB comparisons confirm a small effect of board games over other control comparators at the posttest $\left(d^{*}=0.23\right.$, 95\% CI [0.11-0.36]) and a very small and trending effect upon delayed follow-up $\left(d^{*}=0.12,95 \%\right.$ CI $[-0.01$ to 0.24$\left.]\right)$.

Biological health indicators. There was a small-to-moderate effect of board games on biological health indicators (e.g., zBMI, diabetes indicators) measured immediately after the

Table 8. Effect Size Details for Studies Measuring Attitudes and/or Beliefs

\begin{tabular}{|c|c|c|c|c|c|c|}
\hline \multirow[b]{2}{*}{ Source } & \multirow[b]{2}{*}{ Comps } & \multirow[b]{2}{*}{$\operatorname{RoB}$} & \multicolumn{2}{|l|}{ Postintervention } & \multicolumn{2}{|l|}{ Delayed follow-up } \\
\hline & & & ES (95\% CI low to high) & $\begin{array}{c}\text { Weight } \\
(\%)\end{array}$ & ES (95\% CI low to high) & $\begin{array}{c}\text { Weight } \\
(\%)\end{array}$ \\
\hline \multicolumn{7}{|c|}{ A. Synthesis of data at all RoB } \\
\hline Khazaal et al. ${ }^{43}$ & 10 & Low/unclear & $0.13(-0.01$ to 0.27$)$ & 54.0 & $0.05(-0.08$ to 0.19$)$ & 79.7 \\
\hline Lennon and Coombs ${ }^{36}$ & 1 & Unclear & $0.03(-0.28$ to 0.33$)$ & 11.5 & - & - \\
\hline Okitika et al. ${ }^{41}$ & 1 & High & $0.09(-0.22$ to 0.40$)$ & 11.1 & - & - \\
\hline Viggiano et al. ${ }^{20}$ & 1 & Low & $0.27(0.06-0.48)$ & 23.4 & $0.09(0.18-0.35)$ & 20.3 \\
\hline Synthesized effect & & & $0.15(0.05-0.25)^{\mathrm{a}}$ & & $0.06(-0.05 \text { to } 0.18)^{\mathrm{b}}$ & \\
\hline \multicolumn{7}{|c|}{ B. Synthesis of data at low RoB } \\
\hline Khazaal et al. ${ }^{43}$ & 9 & Low & $0.22(0.06-0.37)$ & 65.8 & $0.12(-0.02$ to 0.27$)$ & 76.6 \\
\hline Viggiano et al. $^{20}$ & 1 & Low & $0.27(0.06-0.48)$ & 34.2 & $0.09(0.18-0.35)$ & 23.4 \\
\hline Synthesized effect & & & $0.23(0.11-0.36)^{\mathrm{c}}$ & & $0.12(-0.01 \text { to } 0.24)^{\mathrm{d}}$ & \\
\hline
\end{tabular}

ES (Cohen's $d$ ); "Comps" refers to the number of game-control comparisons that were combined (due to multiple outcome measures or multiple control groups) to form the ES used. "Weight (\%)" refers to the total weight or contribution each study makes to the synthesized effect.

${ }^{\mathrm{a}} \mathrm{Q}=2.04, d f=3, \mathrm{C}=226.75$, Tau $=0.00, I^{2}=0.00, \mathrm{Z}=2.81, P=0.005$.

${ }^{\mathrm{b}} \mathrm{Q}=0.04, d f=1, \mathrm{C}=88.98$, Tau $=0.00, I^{2}=0.00, \mathrm{Z}=1.01, P=0.313$.

${ }^{\mathrm{c}} \mathrm{Q}=0.17, d f=1, \mathrm{C}=111.21$, Tau $=0.00, I^{2}=0.00, \mathrm{Z}=3.68, P<0.001$.

${ }^{\mathrm{d}} \mathrm{Q}=0.06, d f=1, \mathrm{C}=85.49$, Tau $=0.00, I^{2}=0.00, \mathrm{Z}=1.78, P=0.075$. 
Table 9. Effect Size Details for Studies Measuring Health-Related Biological Health Indicators

\begin{tabular}{|c|c|c|c|c|c|c|}
\hline \multirow[b]{2}{*}{ Source } & \multirow[b]{2}{*}{ Comps } & \multirow[b]{2}{*}{$\operatorname{RoB}$} & \multicolumn{2}{|c|}{ Postintervention } & \multicolumn{2}{|c|}{ Delayed follow-up } \\
\hline & & & ES (95\% CI low to high) & Weight (\%) & ES (95\% CI low to high) & Weight (\%) \\
\hline Amaro et al. ${ }^{33}$ & 1 & Unclear & $0.21(-0.20$ to 0.62$)$ & 11.5 & - & - \\
\hline Crawford and Wiltz ${ }^{21}$ & 4 & Unclear & $0.29(0.17-0.41)$ & 43.1 & - & 一 \\
\hline Viggiano et al. ${ }^{20}$ & 1 & Low & $0.47(0.37-0.58)$ & 45.5 & $0.51(0.36-0.67)$ & 100 \\
\hline Synthesized effect & & & $0.37(0.21-0.52)^{\mathrm{a}}$ & & & \\
\hline
\end{tabular}

ES (Cohen's $d$ ); "Comps" refers to the number of game-control comparisons that were combined (due to multiple outcome measures or multiple control groups) to form the ES used. "Weight (\%)" refers to the total weight or contribution each study makes to the synthesized effect.

${ }^{\mathrm{a}} \mathrm{Q}=5.56, d f=2, \mathrm{C}=328.12$, Tau $=0.01, I^{2}=64.04, \mathrm{Z}=4.60, P<0.001$.

intervention $\left(d^{*}=0.37,95 \%\right.$ CI $[0.21-0.52]$, Table 9$)$. Only Viggiano et al. ${ }^{20}$ performed a delayed follow-up measurement, which showed a moderate effect of lower zBMI scores in favor of the game group over a no-intervention group. The comparisons in this category's synthesis showed $45.5 \%$ weight at low risk and the remaining $54.6 \%$ at an unclear risk. Only the comparisons by Viggiano et al. ${ }^{20}$ are at a low RoB, so sensitivity analyses were not performed.

Social functioning. A single study targeted social functioning in patients with schizophrenia with seven subscales. ${ }^{39}$ Although the authors report significant outcomes on a few subscales (e.g., recreational activities), there was no significant effect of the board game on social functioning $(d=0.19$, $95 \%$ CI [ -0.11 to 0.48$], \mathrm{Z}=1.22, P=0.221)$. The RoB associated with the comparisons in this combined ES was unclear.

Anxiety. The effect of a board game intervention on anxiety was assessed in one study by Fernandes et al. in preoperative children and their parents. ${ }^{35}$ The authors did not provide information about variance for the data, which prevented us from calculating ES for anxiety. These comparisons were at an overall high RoB.

Executive functioning. Finally, executive functioning was assessed by Fissler et al. among elderly retirement home patients at risk of dementia. ${ }^{40}$ An overall large but nonsignificant effect of the game intervention program was observed at immediate follow-up $(d=0.88,95 \%$ CI $[-0.19$ to 1.95], $\mathrm{Z}=1.82, P=0.068$ ). This comparison was associated with an unclear RoB.

\section{RoB across studies}

The risk of publication bias across studies was assessed visually with a funnel plot (Fig. 3). Although there is a noticeable lack of studies to support other interventions over board games (dots left of zero), Egger's test was not

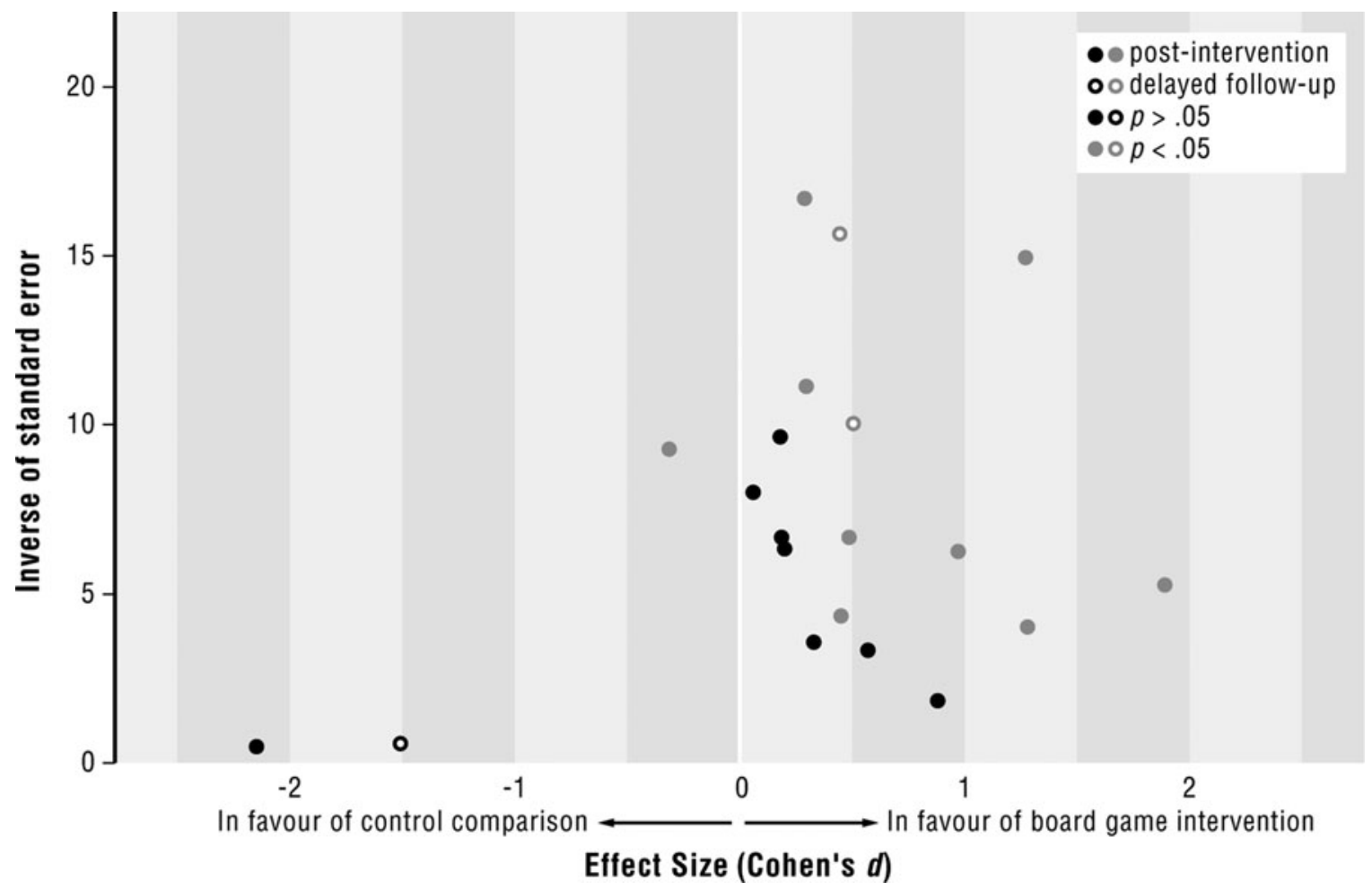

FIG. 3. Funnel plot of effect sizes from postintervention and delayed follow-up comparisons against the inverse of the standard error of the effect, across all outcome categories. 
significant for postintervention comparisons $\left(\beta_{0}=-0.09\right.$, $90 \%$ CI [ -3.84 to 3.64], $\left.d f_{\text {total }}=16, t=-0.05, P=0.964\right)$. Publication bias was also not observed in the majority of the individual outcome categories (Supplementary Data). Lastly, Egger's test was not significant for delayed follow-up comparisons $\left(\beta_{0}=-0.91,90 \% \mathrm{CI}[-6.05\right.$ to 4.24$], d f_{\text {total }}=2$, $t=-1.11, P=0.466)$.

\section{Discussion}

This systematic review and meta-analysis is the first to provide a synthesis on and analysis of nondigital board games for health impacts for users in academic, patient/ hospital, and community settings together. It extends Bochennek et al. review of board games for medical education by also including games for patients and laypeople from a community context. ${ }^{16}$ The findings further contribute to theories about how games can facilitate learning and behavior change..$^{8-11}$ The overall quality of the studies investigated was not high; RoB assessments revealed that $85.7 \%$ of the studies had a high or unclear RoB associated with their methodological designs. Keeping these biases in mind, we have been able to draw some general insights about the impact of board games on health-related outcomes and about potential future directions for research.

\section{Main findings}

The designs of board games evaluated, and the types of measures used to evaluate outcomes across studies were heterogeneous; a finding that is consistent with previous reviews of board games for medical education that also found the topics addressed and game approaches difficult to place in broad categories due to the diversity of examples in the literature. ${ }^{16,18}$ The diversity of approaches and topics addressed in board games was also found in reviews of digital game-based learning and serious games. ${ }^{2,51}$

While the majority of games in this review are applied to behavioral challenges consistent with major healthcare priorities (e.g., reduction in rates of obesity), they typically aim to affect change by conveying knowledge. For instance, Viggiano et al. ${ }^{20}$ targeted lifestyle changes in children by conveying knowledge about healthy diet and exercise. Our meta-analysis showed that board games resulted in significantly more knowledge attainment than other nongame conditions, consistent with findings of meta-analyses in the realm of digital game-based learning. ${ }^{52-55}$ This-along with the null or very small effects measured in self-efficacy and attitudes/beliefs - suggests that the primary value of board games thus far is shown when applied to behavioral problems arising through lack of knowledge or difficulty in communicating health-related concepts, rather than those characterized by the persistence of negative behavior in the presence of knowledge. Even Khazaal et al., ${ }^{43}$ who did not measure knowledge directly, aimed to change smoking behavior through the conveyance of facts about smoking (e.g., costs associated with addiction, biological effects of smoking). However, it should be noted that the lack of analyses of board games applied to situations, wherein negative behavior persists in the face of knowledge precludes conclusions regarding their suitability in these contexts.

Overall, and in many cases as a result of increased knowledge through gameplay, ${ }^{20,33,34,41-43,46}$ health-related behavioral outcomes (e.g., smoking cessation, diet, and lifestyle changes) showed a small-to-moderate postintervention effect in favor of board games, particularly in the self-reported behavior category. This is consistent with studies of videogames targeting health behavior change that generally show positive effects. ${ }^{2,56}$ However, self-reported measures of behavior are particularly vulnerable for bias because they can be associated with social stigmas (e.g., around diet and exercise). ${ }^{57,58}$ Unfortunately, only a single study in our review included an objective measure of behavior. ${ }^{38}$ Ultimately, downstream biological health/patient outcomes, such as reduced zBMI scores, are the desired objectives of behavior-targeting games and indicate realworld behavior change; our synthesis of biological health outcomes demonstrated small-to-moderate effects in this category, highlighting the potential of board games to facilitate real-world change, although only three studies included such outcomes. A meta-analysis investigating the synthesized effects of active videogames on health outcomes also showed small to large effects. ${ }^{59}$

While our analyses suggest that board games can be effective at increasing knowledge, changing behavior and, in turn, affecting biological outcomes, the evidence for improvement of self-efficacy was not significant; this is inconsistent with a meta-analysis of active videogames that showed moderate effects on self-efficacy, ${ }^{59}$ perhaps because players of active videogames experience the behavior firsthand, instead of receiving knowledge about the behavior to apply at a later time, like in the reviewed board games. Furthermore, we can fairly confidently conclude (due to the low RoB and significant synthesized effects) that board games affect attitudes and/or beliefs very little, which contrasts stronger findings in the digital game-based learning literature ${ }^{60}$ Lastly, there is insufficient evidence to conclude whether board games may impact other outcomes in health and medicine, such as anxiety, social functioning, and executive functioning, with only single studies covering these themes. However, game-based studies of other "nonboard" games not included in this review (e.g., Mahjong) have shown some promise in the realm of executive functioning. $^{61-63}$

\section{Limitations}

This meta-analysis is limited by heterogeneity of outcomes used to evaluate the board games, poor methodological design of many of the studies, and the small sample size/ inadequate power of most of the included studies. Synthesizing highly heterogeneous studies (note the high $I^{2}$ values for our various syntheses), is a clear weakness in this metaanalysis. However, heterogeneous outcomes are often examined to come to higher-order generalizations about a topic in question. ${ }^{29,30}$ In this case, we were interested in examining whether board games could be used as a tool to impact outcomes in the domain of health. Therefore, the results should be used as a general summary of the effect across the educational board game literature in different outcomes. Furthermore, because of the limited number of comparisons within each outcome category, we were unable to perform moderator analyses to investigate possible confounding effects of, for example, total play time, primary game mechanic (e.g., question-and-answer vs. action-and-consequence), or 
target audience (e.g., adults or children). It should finally be noted that, since studies with larger samples (and therefore less variance) tended to contribute more toward synthesized effects (e.g., Viggiano et al. ${ }^{20}$ accounted for $\sim 40 \%$ of the weight in self-reported behavior; Khazaal et al. accounted for $54 \%$ of the weight in attitudes and beliefs), our reported effects may be more representative of the types of board games or play contexts found in these more robust studies.

Another limitation of the data synthesis is that, while we examined outcomes from studies with control/comparison groups, some of these included research designs that did not randomize participants to treatment and control groups. The randomized trial is considered the Gold Standard for determining causality in evaluating the impact of interventions on outcomes. ${ }^{4}$ Until results from larger and higher quality, randomized, controlled trials of board game interventions in healthcare are available, the research results presented in this review represent the best strategy for appraising the evidence, while considering the inherent bias in the studies evaluated.

A further limitation is that the findings reported do not consider preintervention results because (1) some studies did not include baseline measurements and (2) most studies did not report variance for pre to postintervention change, thus excluding pre-post improvement information from ES calculations; this precluded our ability to evaluate whether or not differences between treatment and control groups observed at the postintervention may have been related to preexisting differences at baseline. However, it should be noted that effects with baseline imbalances (or no reported baseline measurements at all) were excluded from sensitivity analyses as they fell into the high or unclear RoB categories. Finally, the findings from this study are also limited due to missing data from studies; there was missing data from 11/88 postintervention comparisons where the authors did not include enough information for ES to be calculated (all these studies are at an unclear to high RoB).

Despite these limitations, it should be noted that an overall strength of this review is that it synthesizes data across diverse populations to estimate the impact that board games have had on various health-related outcomes, which has not previously been done in the literature.

\section{Future directions}

Our suggestions based on our critical review of the studies are consistent with previous games for health guidelines that call for the use of randomized controlled trials with adequate sample sizes to clarify the causal role of the intervention's impact on outcomes. ${ }^{56,64}$ Studies should also aim to measure behavior through direct means or consecutively logged activity to prevent biases associated with self-reports and, when possible, include more objective biological outcomes (e.g., zBMI) to corroborate behavior findings in a standard way across studies.

Furthermore, as discussed above, a main finding of this review was that the majority of board games targeting healthrelated behaviors did so through conveying new knowledge. Future research might investigate whether a board game might be effective in changing persistent, negative behaviors in the presence of knowledge.
Finally, a qualitative interpretation of the included studies would suggest that board games integrating a question-and-answer mechanic (i.e., trivia genre; a popular gaming pattern implemented by most of the included studies) ${ }^{19,31,32,36,42-45,47,49}$ have potential to lead to significant gains in knowledge; this is consistent with other research regarding the impact of self-testing strategies on knowledge consolidation in nongaming contexts. ${ }^{65,66}$ However, there appears to be a lack of board games that incorporate learning and gaming mechanics in more complex ways (e.g., through action-and-consequence), ${ }^{20,33,34,43}$ which limits our understanding of the different ways board games can be designed to support learning. Future games as educational tools should attempt to integrate more complex design strategies and explore whether or not existing digital game design frameworks (e.g., Learning Mechanics-Game Mechanics model, or the Activity Theory Model of Serious Games) ${ }^{67,68}$ can be applied to justify design decisions and advance our understanding in this area. Moreover, game efficacy should be examined through studies designed to clarify whether mechanisms of the board game itself (e.g., cooperative or competitive) or the context of its delivery (e.g., in a clinic, in a school setting) is responsible for the impacts observed in carefully designed studies; while such investigations are inherently more difficult to perform, the importance of asking more design-oriented questions is well recognized. ${ }^{53,69}$

\section{Conclusion}

In sum, this systematic review updates and extends previous reviews of board games for health. Although the findings of this meta-analysis are limited, given the current state of evaluations of board games for health in the literature, they do show preliminary evidence for the use of board games to improve knowledge in health outcomes. Future efforts to develop board games should focus on directly targeting behaviors related to downstream biological health outcomes, exploring alternative game design strategies to the trivia-genre, and evaluating board game interventions using rigorous scientific methods. Once knowledge about the overall efficacy of board games is better established, healthcare professionals, patients, students and community members can benefit from this engaging approach to promote health and medical outcomes.

\section{Acknowledgments}

The authors wish to thank Ouarda Yvray for helpful comments on the review. This work was supported by Pfizer and the Social Sciences and Humanities Research Council of Canada through a Michael Smith Foreign Study Supplement.

\section{Author Disclosure Statement}

No competing financial interests exist.

\section{References}

1. Annetta LA. "The 'I's' have it: A framework for serious educational game design": Correction to Annetta (2010). Rev Gen Psychol 2010; 14:105-112.

2. Baranowski T, Buday R, Thompson DI, Baranowski J. Playing for real. Video games and stories for health-related behavior change. Am J Prev Med 2008; 34:74-82.e10. 
3. DeSmet A, Van Cleemput K, Bastiaensens S, et al. Bridging behavior science and gaming theory: Using the Intervention Mapping Protocol to design a serious game against cyberbullying. Comput Human Behav 2016; 56: 337-351.

4. Kato PM. Video games in health care: Closing the gap. Rev Gen Psychol 2010; 14:113-121.

5. Khazaal Y, Chatton A, Dieben K, et al. Reducing delusional conviction through a cognitive-based group training game: A multicentre randomized controlled trial. Front Psychiatry 2015; 6:1-10.

6. Merry SN, Stasiak K, Shepherd M, et al. The effectiveness of SPARX, a computerised self help intervention for adolescents seeking help for depression: Randomised controlled non-inferiority trial. BMJ 2012; 344:1-16.

7. Cardoso-Leite P, Bavelier D. Video game play, attention, and learning. Curr Opin Neurol 2014; 27:185-191.

8. Boyle EA, Connolly TM, Hainey T, Boyle JM. Engagement in digital entertainment games: A systematic review. Comput Human Behav 2012; 28:771-780.

9. Kapp KM. The Gamification of Learning and Instruction: Game-Based Methods and Strategies for Training and Education. San Francisco, CA: John Wiley \& Sons, Ltd.; 2012. $336 \mathrm{p}$.

10. Lu AS, Baranowski T, Thompson D, Buday R. Story immersion of videogames for youth health promotion: A review of literature. Games Health J 2012; 1:199-204.

11. Paras B, Bizzocchi J. Game, motivation, and effective learning: An integrated model for educational game design. Digit Games Res Assoc Conf 2005; 3. http://www.digra.org/ digital-library/publications/game-motivation-and-effectivelearning-an-integrated-model-for-educational-game-design/

12. Sardone NB, Devlin-Scherer R. Let the (board) games begin: Creative ways to enhance teaching and learning. Clear House A J Educ Strateg Issues Ideas 2016; 89:215222.

13. Bratton SC, Ray D, Rhine T, Jones L. The efficacy of play therapy with children: A meta-analytic review of treatment outcomes. Prof Psychol Res Pract 2005; 36:376-390.

14. Nickerson ET, O'Laughlin KB. It's fun-But will it work?: The use of games as a therapeutic medium for children and adolescents. J Clin Child Psychol 1980; 9:78-81.

15. Wilde J. The effects of the Let's Get Rational board game on rational thinking, depression, and self-acceptance in adolescents. J Ration Cogn Ther 1994; 12:189-196.

16. Bochennek K, Wittekindt B, Zimmermann S-Y, Klingebiel T. More than mere games: A review of card and board games for medical education. Med Teach 2007; 29:941948.

17. Akl EA, Pretorius RW, Sackett K, et al. The effect of educational games on medical students' learning outcomes: A systematic review: BEME Guide No 14. Med Teach 2010; 32:16-27.

18. Blakely G, Skirton H, Cooper S, et al. Educational gaming in the health sciences: Systematic review. J Adv Nurs 2009; 65:259-269.

19. Wanyama JN, Castelnuovo B, Robertson G, et al. A randomized controlled trial to evaluate the effectiveness of a board game on patients' knowledge uptake of HIV and sexually transmitted diseases at the Infectious Diseases Institute, Kampala, Uganda. JAIDS J Acquir Immune Defic Syndr 2012; 59:253-258.

20. Viggiano A, Viggiano E, Di Costanzo A, et al. Kaledo, a board game for nutrition education of children and ado- lescents at school: Cluster randomized controlled trial of healthy lifestyle promotion. Eur J Pediatr 2015; 174:217228.

21. Crawford P, Wiltz S. Participation in the journey to life conversation map improves control of hypertension, diabetes, and hypercholesterolemia. J Am Board Fam Med 2015; 28:767-771.

22. Liberati A, Altman DG, Tetzlaff J, et al. The PRISMA statement for reporting systematic reviews and metaanalyses of studies that evaluate health care interventions: Explanation and elaboration. PLoS Med 2009; 6:1-27.

23. Moher D, Liberati A, Tetzlaff J, et al. Preferred reporting items for systematic reviews and meta-analyses: The PRISMA statement. PLoS Med 2009; 6:1-6.

24. board game (noun). Merriam Webster Dictionary. 2018 [cited May 5, 2018]. https://www.merriam-webster.com/ dictionary/board game?utm_campaign $=$ sd\&utm_medium $=$ serp\&utm_source = jsonld (accessed May 15, 2018).

25. Biernacki P, Waldorf D. Snowball Sampling: Problems and techniques of chain referral sampling. Sociol Methods Res 1981; 10:141-163.

26. Cohen J. Statistical Power Analysis for the Behavioral Sciences. 2nd ed. New York, NY: Academic Press; 1977.

27. Borenstein M, Hedges LV, Higgins JPT, Rothstein HR. Converting among effect sizes. In: Introduction to MetaAnalysis 2009, pp. 45-49.

28. Higgins JPT, Green S, editors. Cochrane Handbook for Systematic Reviews of Interventions. v. 5.1.0. The Cochrane Collaboration; 2011. www.handbook.cochrane.org (accesed November 1, 2017).

29. Cooper H, Hedges LV, Valentine JC, eds. The Handbook of Research Synthesis and Meta-Analysis. 2nd ed. New York, NY: Russell Sage Foundation; 2009, 632 p.

30. Borenstein M, Hedges LV, Higgins JPT, Rothstein HR. When does it make sense to perform a meta-analysis? In: Introduction to Meta-Analysis 2009, pp. 357-364.

31. Charlier N, De Fraine B. Games based learning as a vehicle to teach new content: A case study. Proceedings of European Conference on Games Based Learning 2010, pp. 4046.

32. Charlier N, De Fraine B. Game-based learning as a vehicle to teach first aid content: A randomized experiment. J Sch Health 2013; 83:493-499.

33. Amaro S, Viggiano A, Di Costanzo A, et al. Kalèdo, a new educational board-game, gives nutritional rudiments and encourages healthy eating in children: A pilot cluster randomized trial. Eur J Pediatr 2006; 165:630-635.

34. Czuchry M, Sia TL, Dansereau DF. Preventing alcohol abuse: An examination of the "Downward Spiral" game and educational videos. J Drug Educ 1999; 29:323-335.

35. Fernandes SC, Arriaga P, Esteves F. Providing preoperative information for children undergoing surgery: A randomized study testing different types of educational material to reduce children's preoperative worries. Health Educ Res 2014; 29:1058-1076.

36. Lennon JL, Coombs DW. The utility of a board game for dengue haemorrhagic fever health education. Health Educ 2007; 107:290-306.

37. Udin RD, Kuster CG. A board game for sensitizing dental students to children with special needs. J Dent Educ 1985; 49:111-114.

38. Moyer JA, Nelson DL. Replication and resynthesis of an occupationally embedded exercise with adult rehabilitation patients. Isr Soc Occup Ther 1998; 7:E57-E73. 
39. Torres A, Mendez LP, Merino H, Moran EA. Improving social functioning in schizophrenia by playing the train game. Psychiatr Serv 2002; 53:799-801.

40. Fissler P, Küster O, Schlee W, Kolassa I-T. Novelty interventions to enhance broad cognitive abilities and prevent dementia. Prog Brain Res 2013; 207:403-434.

41. Okitika TA, Barnabas RV, Rue T, et al. "Polio Eradication" game may increase public interest in global health. Games Heal] 2015; 4:195-201.

42. Burghardt KJ, Bowman MR, Hibino M, et al. Using educational games to promote the seeking of a pharmacist and to teach key medication use messages: Results from an inner city health party. Res Soc Adm Pharm 2013; 9:542552.

43. Khazaal Y, Chatton A, Prezzemolo R, et al. Impact of a board-game approach on current smokers: A randomized controlled trial. Subst Abuse Treat Prev Policy 2013; 8:3.

44. Anyanwu EG. Anatomy adventure: A board game for enhancing understanding of anatomy. Anat Sci Educ 2014; 7: 153-160.

45. Maclachlan M, Chimombo M, Mpemba N. AIDS education for youth through active learning: A school-based approach from Malawi. International Journal of Educational Development 1997; 17:41-50.

46. McKay RB, Levine DM, Bone LR. Community organization in a school health education program to reduce sodium consumption. J Sch Health 1985; 55:364-366.

47. Bartfay WJ, Bartfay E. Promoting Health in Schools through a Board Game. West J Nurs Res 1994; 16:438-446.

48. Ogunsile S, Ogundele B. Effect of game-enhanced nutrition education on knowledge, attitude and practice of healthy eating among adolescents in Ibadan, Nigeria. Int $\mathbf{J}$ Heal 2016; 5240:1-10.

49. Swiderska N, Thomason E, Hart A, Shaw BN. Randomised controlled trial of the use of an educational board game in neonatology. Med Teach 2013; 35:413-415.

50. Bandura A. Social cognitive theory: An agentic perspective. Annu Rev Psychol 2001; 52:1-26.

51. Connolly TM, Boyle EA, MacArthur E, et al. A systematic literature review of empirical evidence on computer games and serious games. Comput Educ 2012; 59:661-686.

52. Sitzmann T. A meta-analytic examination of the instructional effectiveness of computer-based simulation games. Pers Psychol 2011; 64:489-528.

53. Clark DB, Tanner-Smith EE, Killingsworth SS. Digital games, design, and learning: A systematic review and meta-analysis. Rev Educ Res 2016; 86:79-122.

54. Wouters $P$, van Nimwegen $C$, van Oostendorp $H$, van der Spek ED. A meta-analysis of the cognitive and motivational effects of serious games. J Educ Psychol 2013; 105: 249-265.

55. Lau HM, Smit JH, Fleming TM, Riper H. Serious games for mental health: Are they accessible, feasible, and effective? A systematic review and meta-analysis. Front Psychiatry 2017; 7:13.

56. Charlier N, Zupancic N, Fieuws S, et al. Serious games for improving knowledge and self-management in young people with chronic conditions: A systematic review and meta-analysis. J Am Med Informatics Assoc 2015; 23:230239.

57. Brenner PS, DeLamater JD. Social desirability bias in selfreports of physical activity: Is an exercise identity the culprit? Soc Indic Res 2014; 117:489-504.

58. Klesges LM, Baranowski T, Beech B, et al. Social desirability bias in self-reported dietary, physical activity and weight concerns measures in 8- to 10-year-old AfricanAmerican girls: results from the Girls health Enrichment Multisite Studies (GEMS). Prev Med (Baltim) 2004; 38(suppl.):78-87.

59. Gao Z, Chen S, Pasco D, Pope Z. A meta-analysis of active video games on health outcomes among children and adolescents. Obes Rev 2015; 16:783-794.

60. Vogel JJ, Vogel DS, Cannon-Bowers J, et al. Computer gaming and interactive simulations for learning: A metaanalysis. J Educ Comput Res 2006; 34:229-243.

61. Cheng S, Chan ACM, Yu ECS. An exploratory study of the effect of Mahjong on the cognitive functioning of persons with dementia. Int J Geriatr Psychiatry 2006; 21:611-617.

62. Cheng S-T, Chow PK, Yu ECS, Chan ACM. Leisure activities alleviate mild dementia. Am J Geriatr Psychiatry 2012; 20:904-908.

63. Cheng S-T, Chow PK, Song Y-Q, et al. Mental and physical activities delay cognitive decline in older persons with dementia. Am J Geriatr Psychiatry 2014; 22:63-74.

64. Baranowski T, Blumberg F, Buday R, et al. Games for health for children-Current status and needed research. Games Health J 2016; 5:1-12.

65. Roediger III HL, Butler AC. The critical role of retrieval practice in long-term retention. Trends Cogn Sci 2011; 15: 20-27.

66. Roediger III HL, Agarwal PK, McDaniel MA, McDermott KB. Test-enhanced learning in the classroom: Long-term improvements from quizzing. J Exp Psychol Appl 2011; 17:382-395.

67. Arnab S, Lim T, Carvalho MB, et al. Mapping learning and game mechanics for serious games analysis. Br J Educ Technol 2015; 46:391-411.

68. Carvalho MB, Bellotti F, Berta R, et al. An activity theorybased model for serious games analysis and conceptual design. Comput Educ 2015; 87:166-181.

69. Girard C, Ecalle J, Magnan A. Serious games as new educational tools: How effective are they? A meta-analysis of recent studies. J Comput Assist Learn 2013; 29:207-219.

Address correspondence to: Andrea Gauthier, MScBMC, PhD Candidate Faculty of Medicine Institute of Medical Sciences University of Toronto 3359 Mississauga Road Mississauga Canada L5L $2 A 9$ E-mail: andrea.gauthier@utoronto.ca 